\title{
El principio de igualdad fuente obligatoria de derecho para las autoridades administrativas: reconocimiento de prerrogativas a hijastros de trabajadores oficiales de Ecopetrol S.A. con beneficios convencionales
}

Alexander Mateus Rodríguez
Abogado, Especialista en Derecho Administrativo por la Universidad Santo Tomás Seccional Bucaramanga

Funcionario de la Rama Judicial del Poder Público.Correo electrónico: alexandermateusrodriguez@hotmail.com

\begin{abstract}
Resumen
La Constitución Política y la Jurisprudencia obligan categóricamente que las autoridades administrativas reconozcan los principios constitucionales como fuente obligatoria de derecho. El test de razonabilidad, como ejercicio efectivo de ponderación, permite afirmar que la negación injustificada del principio de igualdad como fuente necesaria de derecho, de la Empresa Ecopetrol S.A., al momento de limitar los beneficios convencionales a los hijastros de empleados oficiales con prerrogativas convencionales, porque no es descendiente natural del trabajador titular del beneficio, desconoce que la familia se forma por vínculos naturales y jurídicos que exigen un trato igualitario de todas las personas que la integran.
\end{abstract}

Palabras clave: Nomoárquica, principialistica, jurisprudencia, igualdad, fuente, razonabilidad.

\begin{abstract}
The Constitution and the Court categorically require that administrative authorities recognize the constitutional principles as binding source of law. The test of reasonableness, as effective weighing exercise, declares that the unjustified denial of the principle of equality as a necessary source of law, on the part of the company Ecopetrol S.A, when conventional limit benefits to stepchildren officers employed with conventional prerogatives, because it's not natural descendant of holder worker benefit. The company doesn't recognize that the family is formed by natural and legal links which require equal treatment of all persons within it.

Keywords: Nomoárquica, principialistica, jurisprudence, equality, power, reasonableness.

Résumé

La Constitution et la Cour exigent catégoriquement que les autorités administratives reconnaissent les principes constitutionnels en tant que source de droit obligatoire. Le critère du caractère raisonnable, en tant qu'exercice réel de pondération, suggère que le refus injustifié de l'entreprise Ecopetrol SA du principe de l'égalité comme une source nécessaire de droit, au moment de limiter les prestations conventionnelles aux beaux-enfants des employés, car ils ne sont pas les enfants naturels des travailleurs bénéficiaires. L'entreprise ignore que la famille est formée par des liens physiques et moraux qui exigent l'égalité de traitement de toutes les personnes qui en font partis.

Mots-clés: Nomoárquica, Principialistica, La jurisprudence, L'égalité, La puissance, Raisonnable.
\end{abstract}





\section{El principio de igualdad fuente obligatoria de derecho para las autoridades administrativas: reconocimiento de prerrogativas a hijastros de trabajadores oficiales de Ecopetrol S.A. con beneficios convencionales*}

Alexander Mateus Rodríguez

\section{INTRODUCCIÓN}

A partir de la promulgación de la Constitución Política de 1991, la sociedad colombiana experimentó el surgimiento de una nueva forma de Estado, que se inclina por realzar la dignidad humana, y desarrollar herramientas que permitan el crecimiento del ser humano, observándolo por encima de las instituciones y entregándole instrumentos indisolubles que pueden ser reclamados de forma expedita, a través de diversas acciones que la carta fundamental reconoce en el interior de su articulado, los cuales obligan a las autoridades administrativas a reconocer los principios constitucionales como fuente obligatoria de derecho. Lo anterior, se encuentra plasmado desde el preámbulo, donde se estableció que la Constitución Política nace con la intención de fortalecer la Unidad Nacional y asegurar a sus integrantes la vida, la convivencia, el trabajo, la justicia, la igualdad, el conocimiento, la libertad y la paz, dentro de un marco jurídico, democrático y participativo que garantice un orden político, económico y social justo, para una sociedad que necesitaba la presentación de un nuevo paradigma que permita superar los daños generados por la desigualdad económica y la misma violencia política, que mancilló la institucionalidad del país y que había alejado a los ciudadanos de sus derechos fundamentales y personalísimos.

Particularmente, el artículo 209 de la Constitución Política desarrolla la principialística del derecho administrativo, al establecer que la función administrativa está al servicio de los intereses generales y se desarrolla apoyada en los principios de igualdad, moralidad, eficacia, entre otros, que buscan efectivizar las labores de la administración frente a los diversos receptores de las actuaciones administrativas,

El presente artículo es producto de la investigación: El principio de igualdad como fuente obligatoria de derecho para las autoridades administrativas en el reconocimiento de las prerrogativas a los hijastros de trabajadores oficiales de la empresa, realizado en la asignatura Metodología de la Investigación, Especialización en Derecho Administrativo, Universidad Santo Tomás Seccional Bucaramanga, bajo la tutoría del docente Yesid Albeiro Sánchez Sandoval. 
que exigen la prestación de un servicio oportuno, lejos de los trámites y que responda con eficiencia a sus necesidades, devolviendo, de esta manera, la credibilidad de las instituciones, necesaria para el establecimiento de un orden justo, y para garantizar la prosperidad general.

Adicionalmente, la Ley 489 de 1998 estableció que el desarrollo de la función administrativa atenderá particularmente los principios constitucionales de buena fe, igualdad, moralidad, celeridad, economía, imparcialidad, eficacia, eficiencia, participación, responsabilidad y transparencia; integrando de esta forma el artículo 209 de la Carta Política.

La nomoárquica fue valorada ampliamente en la Ley 1437 de 2011, establece en la preceptiva 3 que todas las autoridades deberán interpretar y aplicar las disposiciones que regulan las actuaciones y procedimientos administrativos a la luz de los principios consagrados en la Constitución Política, en la Parte Primera de este Código y en las leyes especiales. Adicionalmente, se establece que las actuaciones administrativas se desarrollarán, especialmente, con arreglo a los principios del debido proceso, igualdad, imparcialidad, buena fe, moralidad, participación, responsabilidad, transparencia, publicidad, coordinación, eficacia, economía y celeridad.

Igualmente describe que en virtud del principio de igualdad, las autoridades darán el mismo trato y protección a las personas e instituciones que intervengan en las actuaciones bajo su conocimiento. No obstante, serán objeto de trato y protección especial las personas que por su condición económica, física o mental se encuentran en circunstancias de debilidad manifiesta.

La teoría jurídica alemana desarrollada por Robert Alexy, enseña que los conflictos donde entra en juego el derecho a la igualdad muestran que las normas que lo consagran pueden ser tratadas como principios, erigiéndose como normas cuya aplicación en un caso concreto depende de la ponderación que se haga frente a los principios que con él colisionan. Además, resulta forzoso resaltar que el profesor alemán ha desarrollado con amplia nitidez el principio de proporcionalidad con sus tres sub-principios: idoneidad (la intervención debe procurar un fin constitucional), la necesidad (la afectación al principio debe ser la menos gravosa de entre las disponibles), y proporcionalidad en sentido estricto (precisando que la afectación debe compensarse o equilibrarse con beneficios). Para Alexy (2012), los principios son mandatos de optimización que se caracterizan porque pueden cumplirse en diferente grado y que la medida debida de su cumplimiento no solo depende de las posibilidades reales, sino también de las jurídicas.

Es oportuno citar al doctor Abraham Zamir Bechara Llanos, quien en el texto denominado La ponderación y los derechos fundamentales, también escudriña la obra del profesor Robert Alexy Teoría de los derechos fundamentales, al resaltar textualmente lo siguiente: 
La ley de la ponderación ${ }^{1}$ apunta primero a la importancia de la satisfacción del principio contrapuesto, y además en segundo orden formula un mandato ${ }^{2}$, lo relevante es la importancia de las consideraciones de los principios, y de informidad con su método la ponderación plantea una regla de cómo ha de hacerse ese análisis, que arroje una ponderación de principios y su fórmula a la aplicación concreta del principio avante, en un juicio racional y objetivo que nace del estudio de los mecanismos tanto argumentativos como lógicos y herramientas de inferencia, que van a permitir al juzgador o interprete, hacer el desarrollo de los principios que se ponderan, es así como $^{3}$ se propone la utilización de curvas de indiferencia de segundo grado, llevadas a un meta nivel argumentativo para su aplicación (pp. 139-140).

Ronald Dworkin (1989, p. 78) señaló lo siguiente:

Cuando los principios se interfieren (la política de protección de los consumidores de automóviles interfieren con los principios de libertad de contratación, por ejemplo) quien debe resolver el conflicto tiene que tener en cuenta el peso relativo de cada uno. En esto no puede haber por cierto una medición exacta y el juicio respecto de si un principio o directriz en particular es más importante que otro ser, con frecuencia motivo de controversia. Sin embargo, es parte esencial del concepto de principio el que tenga esta dimensión, que tenga sentido, qué importancia o qué peso tiene).

Así mismo, Dworkin entiende que el principio se separa claramente de la concepción, en cuanto él es directamente sacado de las realidades objetivas, refiriéndose a las consideraciones morales, políticas, sociales, económicas, que las denomina como la sustancia fecunda de la vida del derecho.

Para Luigi Ferrajoli (2005) la superlativa importancia de los principios constitucionales se evidencia en la siguiente afirmación:

La subordinación de la ley a los principios constitucionales equivale a introducir una dimensión sustancial, no sólo en las condiciones de validez de las normas, sino también en la naturaleza de la democracia, para la que representa un límite, a la vez que la completa. Un límite porque a los derechos constitucionalmente establecidos corresponden a prohibiciones y obligaciones impuestas a los poderes de la mayoría, que de otra forma serían absolutos. Y la completa porque estas mismas prohibiciones y obligaciones se configuran como otras tantas garantías de los derechos de todos, frente a los abusos de tales poderes que -como la experiencia enseña-podrían de otro modo arrollar, junto con los derechos, al propio método democrático (pp. 18-19).

1 En ocasiones cuando de ponderaciones de derecho constitucional se trata, debe tenerse en cuenta que la aplicación de un principio en colisión va a llevar siempre a la no intervención del principio contrapuesto, que por su menor peso en el caso concreto no tendrá relevancia para el resultado.

2 El mandato que opera como un segundo orden dentro de la ley de la ponderación es aquel que según la fórmula del peso será aplicado en el caso concreto de optimización conforme a las posibilidades fácticas para su real efectividad de aplicación.

3 Llamado como una meta nivel en la utilización de curvas de indiferencia de segundo grado para fundamentar sus ponderaciones de principios de rango constitucional. 
En Sentencia C-126 de 1998 se manifestó que: "los principios constitucionales, a pesar de tener una forma de interpretación y aplicación diversa a las reglas, pues están sujetos a un ejercicio de ponderación, no por ello dejan de ser normas constitucionales, por lo cual deben ser respetados por la ley. Por ende, una disposición legal incompatible con un principio constitucional debe ser declarada inexequible, en caso de que no admita una interpretación conforme a la Carta. Esta Corporación ha señalado que la fuerza normativa de los principios y valores constitucionales es tan clara que incluso habría que retirar del ordenamiento aquellas disposiciones que vulneran el Preámbulo, ya que este forma parte de la Carta y "goza de poder vinculante en cuanto sustento del orden que la Carta instaura y, por tanto, toda norma -sea de índole legislativa o de otro nivel-que desconozca o quebrante cualquiera de los fines en él señalados, lesiona la Constitución porque traiciona sus principios"

En Sentencia C-539 de 2011 se reiteró que la jurisprudencia constitucional ha precisado que:

Todas las autoridades se encuentran sometidas al "imperio de la ley" lo cual significa por sobre todo al imperio de la Constitución, de conformidad con los artículos 2 y 4 Superiores, (i) la tarea de interpretación constitucional no es tarea reservada a las autoridades judiciales, y (iii) que dicha interpretación y aplicación de la ley y de la Constitución debe realizarse conforme a los criterios determinados por el máximo tribunal competente para interpretar y fijar el contenido y alcance de los preceptos de la Constitución. Esta obligación por parte de las autoridades administrativas de interpretar y aplicar las normas a los casos en concreto de conformidad con la Constitución y con el precedente judicial constitucional fijado por esta Corporación, ha sido reiterada en múltiples oportunidades por esta Sala, poniendo de relieve el deber de las autoridades administrativas de ir más allá de las normas de inferior jerarquía para aplicar principios, valores y derechos constitucionales, y de aplicarlos en aras de protegerlos y garantizarlos.

Igualmente, se indicó en el precedente citado que la función definitiva en esta materia corresponde a la Corte Constitucional, conforme se desprende del artículo 241 de la Constitución. Así, al ser guardiana de la supremacía e integridad de la Carta, la interpretación que la Corte haga del texto constitucional es vinculante para todos los operadores jurídicos, sea la administración o los jueces. Siguiendo la misma teleología, se indicó en el referente transcrito que en relación con la obligatoriedad y alcance de la doctrina constitucional, la jurisprudencia de esta Corte ha aclarado que esta deviene de que la Constitución es norma de normas, y el precedente

4 Sentencia C-479 de 1992. M.P. José Gregorio Hernández Galindo y Alejandro Martínez Caballero. Consideración de la Corte No 3. 
constitucional sentado por la Corte Constitucional como guardiana de la supremacía de la Carta tiene fuerza vinculante no solo para la interpretación de la Constitución, sino también para la interpretación de las leyes que obviamente debe hacerse de conformidad con la Carta, y concluye que las sentencias de la Corte Constitucional constituyen para las autoridades administrativas una fuente obligatoria de derecho.

Con fundamento en lo anterior, se afirma forzosamente que las autoridades administrativas deben aplicar en sus actuaciones el principio de igualdad ${ }^{5}$, elaborando objetivamente el test de razonabilidad, establecido para materializar derechos de personas que se encuentran en una posición desventajada, frente a situaciones de derecho similares, que exigen el reconocimiento oportuno de derechos establecidos en la ley o instrumentos convencionales. En el caso de los trabajadores oficiales, especialmente los vinculados a la Empresa Ecopetrol S.A., gozan de diversos beneficios convencionales, que mejoran ostensiblemente sus condiciones materiales de existencia, y que se extienden a los beneficiarios reconocidos en los instrumentos normativos. Empero, se brinda un trato injustificado a los hijastros que conforman la familia del trabajador, quienes dependen absolutamente del beneficiario directo, pero se desconoce la posición que ocupa en el interior del hogar. En estos eventos es obligatoria la aplicación de los principios contenidos en el artículo 209 de la Constitución Política, porque permiten acercar a los ciudadanos a la norma constitucional, la cual exige posiciones incrementalistas en materia de reconocimiento de derechos personalísimos del ser, que se encuentren en una situación de vulnerabilidad, que limiten su crecimiento económico y espiritual por la ausencia de oportunidades reales que permitan igualar sus derechos frente a los privilegios o prerrogativas reconocidas a individuos que se encuentren en iguales condiciones de existencia.

$5 \quad$ En la Sentencia T-256/93 (M.P. Eduardo Cifuentes Muñoz) dijo: “17. El derecho de igualdad ante la ley abarca dos hipótesis claramente distinguibles: la igualdad en la ley y la igualdad en la aplicación de la ley. La primera está dirigida a impedir que el Legislador o el Ejecutivo en ejercicio de su poder reglamentario concedan un tratamiento jurídico a situaciones de hecho iguales sin que exista para ello una justificación objetiva y razonable. La segunda, en cambio, vincula a los jueces y obliga a aplicar las normas de manera uniforme a todos aquellos que se encuentren en la misma situación, lo que excluye que un mismo órgano judicial modifique arbitrariamente el sentido de decisiones suyas anteriores".

"La igualdad en la aplicación de la ley por parte de los órganos judiciales guarda íntima relación con el derecho fundamental a recibir la misma protección y trato de las autoridades (CP art. 13). En este orden de ideas, un mismo órgano judicial no puede otorgar diferentes consecuencias jurídicas a dos o más situaciones de hecho iguales, sin que exista una justificación razonable para el cambio de criterio".

"La desigual aplicación de la ley se concreta, en consecuencia, no obstante existir una doctrina jurisprudencial aplicable a supuestos de hecho similares -término de comparación- el órgano que profirió el fallo se aparta de su criterio jurídico previo de forma no razonada o arbitraria, dando lugar a fallos contradictorios y allanando el camino a la inseguridad jurídica y a la discriminación". 


\section{TRÍPTICO JURISPRUDENCIAL DEL PRINCIPIO DE IGUALDAD}

En la Sentencia C-818 de 2010 se estableció que la igualdad cumple un triple papel en nuestro ordenamiento constitucional por tratarse simultáneamente de un valor, de un principio y de un derecho fundamental. De la misma manera, se indicó que este múltiple carácter se deriva de su consagración en preceptos de diferente densidad normativa que cumplen distintas funciones en nuestro ordenamiento jurídico. La anterior distinción la fundamenta la Corte Constitucional, con lo descrito en el preámbulo constitucional donde se establece entre los valores que pretende asegurar el nuevo orden constitucional la igualdad, mientras que en el artículo 13 de la Carta ha sido considerado como la fuente del principio fundamental de igualdad y del derecho fundamental de igualdad. Adicionalmente, se indicó que existen otros mandatos de equidad dispersos en el texto constitucional, que en su caso actúan como normas especiales que concretan la ecuanimidad en ciertos ámbitos definidos por el Constituyente.

También se destacó en la sentencia comentada otro aspecto de la igualdad que debe ser señalado, y que carece de contenido material específico; ergo, a diferencia de otros principios constitucionales o derechos fundamentales, no protege ningún ámbito concreto de la esfera de la actividad humana sino que puede ser alegado ante cualquier trato diferenciado injustificado.

Resaltó que frente a la famosa formulación aristotélica de "tratar igual a los iguales y desigual a los desiguales"6, la doctrina y la jurisprudencia se han esforzado en precisar el alcance del principio general de igualdad, indicando que se desprenden dos normas que vinculan a los poderes públicos: por una parte, un mandamiento de tratamiento igual que obliga a dar el mismo trato a supuestos de hecho equivalentes, siempre que no existan razones suficientes para otorgarles un trato diferente, del mismo modo, el principio de igualdad también comprende un mandato de tratamiento desigual que obliga a las autoridades públicas a diferenciar entre situaciones diferentes.

El Alto Tribunal complementó que de los diversos contenidos del principio general de igualdad surgen, a su vez, su derecho general, cuya titularidad radica en todos aquellos que son objeto de un trato diferenciado injustificado o de un trato igual a pesar de encontrarse en un supuesto fáctico especial que impone un trato diferente, se trata, entonces, de un derecho fundamental que protege a sus titulares frente a los comportamientos discriminatorios o igualadores de los poderes públicos, el cual permite exigir no solo no verse afectados por tratos diferentes que carecen de justificación, sino también, en ciertos casos, reclamar contra tratos igualitarios que no tengan en cuenta, por ejemplo, especiales mandatos de protección de origen constitucional.

"Por ejemplo, parece que la justicia consiste en igualdad, y así es, pero no para todos, sino para los iguales; y la desigualdad parece ser justa, y lo es en efecto, pero no para todos, sino para los desiguales" (Aristóteles, 1280). 


\section{El test de razonabilidad como herramienta para la aplicación del principio de igualdad}

La teoría del Test de Razonabilidad y de Proporcionalidad (2001) ${ }^{7}$ se trata de ejercicios de ponderación que permiten al intérprete solucionar problemas jurídicos que no alcanzan a ser resueltos por la ambivalencia y vacíos que presenta la norma, y analizando el efecto irradiador que ejerce el derecho constitucional en las demás ciencias y ramas del poder público, permite que exista una solución oportuna a cada caso. Simplemente es una práctica dialéctica a través del cual se desarrollan una serie de preguntas pedagógicamente enseñadas por la Corte Constitucional y que permiten resolver múltiples problemas jurídicos (Sentencia C-673 de 2001). Puntualmente, se exige que se respondan tres preguntas: ¿Igualdad entre quiénes?, ¿igualdad en qué?, ¿igualdad con base en qué criterios? Como ocurrió en la Sentencia T-629 de 2010, donde la Corte Constitucional realizó un ejercicio similar, y concede derechos laborales, especialmente una licencia de maternidad a una trabajadora sexual, equiparando su labor a la del servicio doméstico, y de acuerdo con el principio del contrato-realidad, se ordenó al propietario del establecimiento nocturno que reconociera los derechos pedidos en protección. De igual forma, esto debe ocurrir en materia administrativa, cuando los ciudadanos soliciten el reconocimiento de derechos, que han sido garantizados a sujetos que se encuentren en situaciones similares frente al Estado.

Jurisprudencialmente se ha reconocido que:

El principio de la igualdad es un concepto objetivo y no formal; él se predica de la identidad de los iguales y de la diferencia entre los desiguales. Se supera así el concepto de la igualdad de la ley a partir de la generalidad abstracta, por el concepto de la generalidad concreta, que concluye con el principio según el cual no se permite regulación diferente de supuestos iguales o análogos y prescribe diferente regulación frente a supuestos distintos. Con este concepto sólo se autoriza un trato diferente si está razonablemente justificado. Se supera también, con la igualdad material, el igualitarismo o la simple igualdad matemática (Sentencia C-042 de 2003).

También, se ha indicado que debe mirarse entonces la naturaleza misma de las

$7 \quad$ Corte Suprema de Estados Unidos: ha sostenido que los tribunales deben enfrentar y resolver la cuestión acerca de si las clasificaciones (diferenciadoras) establecidas en una ley son razonables a la luz de su finalidad (McLaughlin v. Florida. 379 U.S. 184, 191 (1964), citado por Laurence Tribe, American Constitutional Law, Mineola, N.Y The Foundation Press, Press, 1988, p. 1440).

Tribunal Constitucional Federal de Alemania: señaló que la máxima de la igualdad es violada cuando para la diferenciación legal o para el tratamiento legal igual no es posible encontrar una razón razonable (BVerfGE 1, 14 (52), citado por Alexy, p., 391).

Corte Europea de Derechos Humanos: dijo textualmente que una diferenciación es discriminatoria si carece de justificación objetiva y razonable, es decir, si no persigue un fin legítimo o si carece de una relación razonable de proporcionalidad entre los medios empleados y el fin perseguido (Cour Européenne des Droits de l'Home. Arrêt MARCKXX c. Belgique, 1979). Ideas tomadas de la Oficina en Colombia del Alto Comisionado para los Derechos Humanos (2001). 
cosas; ella puede en sí misma hacer imposible la aplicación del principio de la igualdad formal, en virtud de obstáculos del orden natural, biológico, moral o material, según la conciencia social dominante en el pueblo colombiano. Asimismo, la doctrina orienta para corregir desigualdades de hecho, se encarga al Estado de promover las condiciones para que la igualdad sea real y efectiva. Por ello, se exige que se adopten medidas en favor de grupos discriminados o marginados, propendiendo siempre por proteger principalmente a aquellas personas que por su condición económica, física o mental se encuentren en circunstancias de inferioridad, de debilidad manifiesta, de acuerdo al mandato establecido en la preceptiva 13 de la norma superior.

En ese orden de pensamiento, la Corte Constitucional ha venido aplicando en sus fallos diversos métodos para la determinación de posibles vulneraciones al principio constitucional de la igualdad (art. 13 C.P.) (Sentencias T- 422 de 1992, M.P. Eduardo Cifuentes Muñoz; Sentencia C-040 de 1993, M.P. Ciro Angarita Barón; C-230 de 1994, M.P. Eduardo Cifuentes Muñoz; C-410 de 1994, M.P. Carlos Gaviria Díaz; C-445 de 1995, M.P. Alejandro Martínez Caballero; T-352 de 1997, M.P. Eduardo Cifuentes Muñoz; Sentencia C-507 de 1997, M.P. Carlos Gaviria Díaz; C-952 de 2000, M.P. Carlos Gaviria Díaz; C-093 de 2001, M.P. Alejandro Martínez Caballero). Dejando claro que entre dichos métodos se encuentra el test de razonabilidad. Además, se ha establecido que este es solo un método para la determinación de vulneraciones del principio de igualdad. También se ha entendido que pueden existir otros métodos para alcanzar dicha finalidad, por lo que el alto tribunal solo opta por aplicar el test de razonabilidad en la medida que se muestra como un método idóneo, más no exclusivo. Lo que ha llevado a sostener que el principio de igualdad no establece una equidad mecánica ni automática. La Corte interpreta así el principio de igualdad, de forma que incluye no solo la orden de tratar de la misma manera a los semejantes sino también la de tratar distintamente a los desiguales, lo que exige se respondan tres interrogantes: ¿igualdad entre quiénes?, ¿igualdad en qué?, ¿igualdad con base en qué criterios? (Sentencia C-673 de 2001). Son preguntas que deben resolverse en cada caso para afirmar indubitablemente si existe o no vulneración del derecho a la igualdad.

\section{EXAMEN DE PROPORCIONALIDAD DEL TRATO DESIGUAL EN EL CASO CONCRETO}

Se afirma que la noción de proporcionalidad sirve de apoyo de la ponderación entre principios constitucionales cuando: "Dos principios entran en colisión, porque la aplicación de uno implica la reducción del campo de aplicación del otro, corresponde al juez constitucional determinar si esa reducción es proporcionada, a la luz de la importancia del principio afectado" (Sentencia T-403 de 1992).

Para materializar la aplicación del principio de igualdad en el caso de los hijastros de los trabajadores de Ecopetrol S.A, que reclamen el reconocimiento de derechos convencionales, debe integrarse lo establecido en la sentencia T-1035 de 2006, donde 
la Corte Constitucional enseñó que el artículo 44 de la Carta Política prevé que los menores de edad son beneficiarios, tanto de derechos establecidos en el texto Constitucional como en tratados internacionales ratificados por Colombia y señala el carácter prevalente de los mismos. En este mismo orden de ideas, se indicó que dadas las condiciones de vulnerabilidad de los niños y la necesidad de cuidado, la jurisprudencia constitucional ha reconocido que aquellos tienen estatus de sujetos de especial protección constitucional.

Además, en la Sentencia T-068 de 2011, la Corte Constitucional manifestó que el artículo 42 de la Constitución establece a la familia como núcleo esencial de la sociedad, la cual puede constituirse por vínculos naturales, jurídicos -como el matrimonio-, o por la voluntad libre y responsable de conformarla. También, se indicó que un componente transversal que abarca el concepto de familia en el ordenamiento jurídico colombiano es el de pluralidad.

Sobre el tema de la igualdad entre la familia, la Corte se pronunció en la Sentencia T-326 de 1993 (M.P. Antonio Barrera Carbonell), respecto a unas peticionarias que vivían en unión libre, tenían hijos y dependían económicamente de sus compañeros, pero luego de que estos fueran incorporados al Ejército, se vieron desprotegidas y privadas de los recursos económicos que proveían sus compañeros, a quienes no los exoneraban del servicio militar por no estar casados, en esa oportunidad se expresó que:

Ahora, cuando la ley exencionó del servicio militar al "varón casado que haga vida conyugal" (Ley la. - 45, f,), estaba defendiendo la familia, que de acuerdo con los criterios éticos-jurídicos que primaban antes de la nueva Constitución, merecía protección únicamente cuando se formaba por el vínculo matrimonial; pero a la luz de los principios profesados por los Constituyentes de 1991, la familia que se origina entre compañeros permanentes, en las condiciones previstas por la ley, merecen también reconocimiento y protección; de manera que el varón en estas condiciones debe ser igualmente objeto de la exención que se otorga al casado.

Si la Constitución equiparó los derechos de la familia, sin parar mientes en su origen, y reconoció también los mismos derechos a los hijos 'habidos en el matrimonio o fuera de él', no puede la ley, ni mucho menos la Administración, mantener o favorecer diferencias que consagren regímenes discriminatorios, porque ello significa el quebrantamiento ostensible de la Carta al amparo de criterios éticos e históricos perfectamente superados e injustos.

La Corte Constitucional en la Sentencia T-536 de 1999 (Sentencia T-536 de 1999, M.P. Vladimiro Naranjo Mesa) estudió un caso en el que el actor consideraba que el artículo 27 de la Ley 21 de $1982^{8}$ excluía del subsidio familiar a los hijastros que llegaran mediante la familia constituida por la unión marital de hecho, pues solo lo

8 "Por la cual se modifica el régimen del Subsidio Familiar y se dictan otras disposiciones". 
otorgaban a aquellos hijastros del vínculo matrimonial, razón por la cual esta Corte inaplicó la norma para proteger los derechos de la familia y del menor, fundada, entre otros argumentos:

Resulta manifiestamente contraria a la Constitución, y por ello debe ser inaplicada. Si el constituyente quiso equiparar la familia que procede del matrimonio con la familia que surge de la unión de hecho, y a los hijos nacidos dentro o fuera del matrimonio, forzoso es concluir que proscribe cualquier tipo de discriminación procedente de la clase de vínculo que da origen a la familia. Por lo tanto, establecer que son 'hijastros' los hijos que aporta uno de los cónyuges al matrimonio, pero que no lo son los que aporta el compañero a una unión de hecho, se erige en un trato discriminatorio que el orden jurídico no puede tolerar"9.

Similarmente, en la Sentencia C-093 de 2001, la Corte reiteró que el derecho a tener una familia es un presupuesto para la materialización de otros derechos fundamentales, especialmente del niño, pues los lazos de afecto y solidaridad contribuyen a la formación integral de una persona, quien edifica allí un espacio privilegiado en donde desarrolla criterios de identidad personal y social. En la Sentencia T-587 de 98, M.P. Eduardo Cifuentes Muñoz, la Corte consideró lo siguiente:

En este sentido, puede afirmarse que la vulneración del derecho a la familia constituye una amenaza seria contra derechos fundamentales como el de la integridad física, la salud, a crecer en un ambiente de afecto y solidaridad, a una alimentación equilibrada, a la educación, a la recreación y a la cultura. Un niño expósito no solo es incapaz de satisfacer sus necesidades básicas, sino que está en una circunstancia especial de riesgo respecto de fenómenos como

9 Línea Jurisprudencial: en este sentido, la Sentencia T-586 de 1999 estudió un caso en que el actor alegó que una Caja de Compensación Familiar tuvo un trato discriminatorio contra su hija, consistente en no ser considerada como hijastra, de su compañera permanente, a efectos de percibir el subsidio familiar en dinero. En esa oportunidad se protegieron los derechos a la familia y a la igualdad de la menor y ordenó a la Caja de Compensación Familiar reconocer y pagar el subsidio familiar en dinero que le correspondía por su condición de hijastra, con el argumento de que: "Por ello la jurisprudencia ha reconocido que, a la luz de la axiología constitucional, son igualmente dignas de respeto y protección las familias originadas en el matrimonio y la[s] conformadas por fuera de este, y que esta igualdad proscribe toda forma de discriminación basada en el origen familiar, ya sea ejercida contra los hijos o contra descendientes de cualquier grado".

En la Sentencia T-1502 de 2000, la Corte señaló que la cobertura familiar en el sistema de seguridad social en salud de los hijastros que aporta el compañero es un derecho que le asiste a la familia, indistintamente de cómo se constituye esta y "Basta entonces que el afiliado cotizante pruebe que esos hijos aportados a la nueva familia por su compañera permanente hacen parte de la familia, son menores, discapacitados o estudian, para que el amparo familiar de la seguridad social les cobije". En la Sentencia C-1033 de 2002 la Corte señaló: "Una interpretación de los artículos 5 y 42 de la Carta Política permite afirmar que la igualdad que propugna la Carta entre las uniones familiares surgidas de vínculos naturales y la conformada por vínculos jurídicos, abarca no solo al núcleo familiar como tal, sino también a cada uno de los miembros que lo componen". 
la violencia física o moral, la venta, el abuso sexual, la explotación laboral o económica y el sometimiento a la realización de trabajos riesgosos. En síntesis, el derecho a formar parte de un núcleo familiar, además de ser un derecho fundamental que goza de especial prelación, constituye una garantía esencial para asegurar la realización de otros derechos fundamentales de la misma entidad, consagrados en el artículo 44 de la Carta [...].

La violación del derecho fundamental de una persona a tener una familia, apareja una degradación tal del ser humano que resulta incompatible con el principio de dignidad protegido por el artículo $1^{\circ}$ de la Carta. Por estas razones, siempre que se respeten las normas básicas de convivencia, la decisión de separarse o de no constituir un núcleo familiar sólo puede ser personal. De otra forma, se estaría convirtiendo al sujeto en un mero instrumento de los caprichos estatales y se le estaría privando de un factor determinante de su más intima individualidad.

También, se debe abordar el tema referente al contenido material de los postulados que reconocen la prevalencia de los derechos de los niños y niñas y su interés superior, donde ha resaltado la jurisprudencia que la aplicación de estos importantes principios se materializa en la aplicación de los mismos dentro del análisis de cada caso concreto. Además, se ha educado al operador constitucional para que, de acuerdo con las particularidades de cada caso individualmente estudiado, se pueda establecer si existe o no desconocimiento de estos principios constitucionales en aras de garantizar su efectiva realización. Particularmente en la Sentencia T-510 del 19 de junio de 2003 se respondió el siguiente interrogante:

¿Qué significa que los niños sean titulares de derechos prevalecientes e intereses superiores? La respuesta únicamente se puede dar desde las circunstancias de cada caso y de cada niño en particular. Esta Corte ha sido enfática al aclarar que el interés superior del menor no constituye un ente abstracto, desprovisto de vínculos con la realidad concreta, sobre el cual se puedan formular reglas generales de aplicación mecánica. Al contrario: el contenido de dicho interés, que es de naturaleza real y relacional, sólo se puede establecer prestando la debida consideración a las circunstancias individuales, únicas e irrepetibles de cada menor de edad, que en tanto sujeto digno, debe ser atendido por la familia, la sociedad y el Estado con todo el cuidado que requiere su situación personal.

Se adiciona a lo anterior que el Alto Tribunal Constitucional, al interpretar el principio de igualdad, dispone no solo la orden de tratar indistintamente a los iguales sino también la de tratar de manera diferente a los desiguales, lo que exige se respondan tres preguntas: ¿igualdad entre quiénes?, ¿igualdad en qué?, ¿igualdad con base en qué criterios?, que al ser utilizadas como parámetros adecuados para resolver el presente asunto revelan un trato injustificado, cuando no se extienden los derechos convencionales reconocidos por la Empresa Ecopetrol S.A., a sus beneficiaros y los niega de forma infundada a los hijastros que acreditan la necesidad de acceder a ellos, 
en las mismas condiciones garantizadas a los demás integrantes de su núcleo familiar. Adicionalmente, se debe acoger el criterio desarrollado por la Corte Constitucional en la Sentencia T-403 de $2011^{10}$, donde dijo que el amparo constitucional no puede ser negado por la inexistencia de una filiación jurídica entre padrastros e hijastros, porque se debe proteger a la familia y a los derechos que a ella le asisten como son un adecuado nivel de vida, la asistencia médica, el cuidado e igual protección de los niños nacidos del matrimonio o fuera de él, y los discapacitados que hagan parte del grupo familiar. También, se inclinó a proteger el derecho a la igualdad de los hijastros en materia de educación, porque con ello se preserva la institución básica de la sociedad que es la familia, en un aspecto específico cuya trascendencia resulta innegable.

Particularmente, en la Sentencia C-577 de 2011 ${ }^{11}$ la Corte Constitucional sostuvo: Tratándose de los hijos, no procede aplicar el mismo régimen al que están sometidas las relaciones de pareja, ya que en materia de filiación rige un principio absoluto de igualdad, porque en relación con los hijos, 'no cabe aceptar ningún tipo de distinción, diferenciación o discriminación, en razón de su origen matrimonial o no matrimonial'.

De la misma manera, en la Sentencia T-292 de 2004 se resaltó la importancia de tener en cuenta el fuerte vínculo que se crea entre los niños y la familia de crianza. Particularmente se enseñó:

El derecho de los niños a tener una familia y no ser separados de ella tiene una especial importancia para los menores de edad, puesto que por medio de su ejercicio se materializan numerosos derechos constitucionales diferentes, que por lo tanto dependen de él para su efectividad: es a través de la familia que los niños pueden tener acceso al cuidado, el amor, la educación y las condiciones materiales mínimas para desarrollarse en forma apta [...] Cuando un niño ha desarrollado vínculos afectivos con sus cuidadores de hecho, cuya ruptura o perturbación afectaría su interés superior, es contrario a sus derechos fundamentales separarlo de su familia de crianza, incluso si se hace con miras a restituirlo a su familia biológica.

10 Sentencia T-403 de 2011, se estimó vulnerado el derecho a la igualdad de las hijas de la pareja de un miembro de la Fuerza Pública (o hijastras como allí se les denomina), a quien se le negaban prerrogativas de acceso a la educación por carecer de filiación con el compañero de su progenitora. Partiendo de los precedentes que en esta decisión se han citado, dijo la Corte: "la interpretación de la norma constitucional contenida en el artículo 42 Superior, lleva a concluir que la familia se protege en la medida en que se extienden derechos a la seguridad social y al subsidio familiar a los hijastros en igualdad de condiciones que a los hijos de la pareja, en consideración a que todos los miembros de las distintas formas de constituir familia son iguales ante el ordenamiento superior, en lo que respecta a estos derechos".

11 Mediante la cual la Corte declaró la exequibilidad del artículo 113 del Código Civil que define el matrimonio y exhorta al Congreso de la República a legislar de manera sistemática y organizada sobre los derechos de las parejas del mismo sexo. 
No puede desecharse que en la Sentencia T-334 de 1998 se dijo que la observancia del principio en manera alguna implica que todas las decisiones de la administración en la aplicación de una norma deban ser necesariamente iguales; pues el dinamismo de los hechos y variedad de situaciones que sirven de sustento a la subsunción de las hipótesis legales puede dar lugar a diversos puntos de vista en la definición de la situación concreta. También, se argumentó que puede existir divergencia de interpretación en las normas por los distintos funcionarios encargados de ejecutarlas; inclusive el funcionario puede variar su criterio sobre la forma en que ha venido interpretando una determinada disposición. En consecuencia, lo que importa, con miras a asegurar la vigencia del principio, es que las interpretaciones que se apartan de un precedente administrativo se justifiquen en forma razonada y suficiente para que el trato diferente sea legítimo.

Por último, es palmario en el asunto estudiado que la actuación administrativa de la empresa prenombrada no responde a los requerimientos diseñados por la doctrina internacional, y por los múltiples referentes jurisprudenciales reseñados arriba, porque excluye de forma injustificada a miembros de una familia, como ocurre con los hijastros de los trabajadores beneficiarios de una Convención Colectiva de Trabajo, que también en el artículo $39^{12}$ presenta una evidente contradicción con lo definido por la Corte Constitucional, al no reconocer los lazos de afecto y solidaridad establecidos entre padrastros e hijastros, desechando que se debe proteger a la familia y los derechos de todos sus integrantes, a gozar de mejores condiciones de vida que consulten criterios que irradien el principio de igualdad, reconocido como un mandato de optimización que debe ser empleado por cualquier autoridad pública o administrativa, integrándolo dentro de sus decisiones para la prestación de un mejor servicio, utilizando criterios de razonabilidad y proporcionalidad que permitan extender mejores beneficios a quien acredite necesitarlos, o que se encuentra en una situación similar, que al ser ponderada con otra experiencia, demande un ejercicio constitucional profundo, estricto que permita establecer un equilibrio dentro de las múltiples desigualdades que impiden el desarrollo armónico de la sociedad, por las evidentes contradicciones que terminan desquebrajando bienes jurídicos, de gran valía, como la estabilidad o conservación y unidad de la familia que debe ser reconocida como aquella establecida por vínculos naturales, jurídicos, crianza y convivencia, donde se tejen sentimientos indisolubles que no pueden ser desconocidos o desechados arbitrariamente. Por el contrario, se deben incrementar

12 Convención Colectiva de Trabajo de la Empresa Ecopetrol S.A. Artículo 39: establece que se entiende como familiares del trabajador los padres, los padres adoptantes, la esposa o compañera permanente inscrita, los hijos menores de dieciocho (18) años, igualmente, los hijos mayores de dieciocho (18) años que estén cursando estudios de enseñanza media, intermedia, universitaria o superior, o aquellos que padecieren cualquier invalidez que les impida trabajar. Las hijas solteras que no tengan hijos, vivan con sus padres y que dependan económicamente del trabajador, también se consideran familiares de estos. Igualmente, para efectos de esta convención, se consideran familiares del trabajador las hijas solteras, menores de veinticinco (25) años que tengan hijos, que vivan con sus padres, que no están trabajando y que dependan económicamente del trabajador. 
las posibilidades de acceso a mayores condiciones de desarrollo personal, como las reconocidas convencionalmente.

Recientemente la Corte Constitucional en Sentencia T-606 del 2 de septiembre de 2013 estudió el problema jurídico desarrollado en el presente trabajo, enseñando que si el principio de igualdad impone a la familia, la sociedad y al Estado brindar el mismo tratamiento a los hijos nacidos dentro o fuera del matrimonio, y en el caso estudiado concluyó que Ecopetrol S.A. discrimina a la hija de la compañera permanente del accionante y su hija de crianza, por carecer de filiación no reconoce que ella hace parte de la familia del trabajador y es beneficiaria de la Convención, ignorando que la niña convive en el núcleo familiar que surge por la voluntad de su madre y el accionante, y que los lazos afectivos que han surgido entre ellos durante varios años de convivencia, convierten al actor en padre de crianza. También estableció que la parte accionada debe otorgar el mismo tratamiento a la hija nacida dentro de la unión marital de hecho y la existente por fuera de ella, y afirmó que como hijastra e hija de crianza se integra al núcleo familiar, imponen a la empresa demandada la obligación de inscribirla como integrante de la familia del trabajador para efectos de la Convención Colectiva de Trabajo 2009-2014.

\section{REFERENCIAS}

Alexy, R. (1993). Teoría de los derechos fundamentales. Madrid: Centro de Estudios Constitucionales.

Bechara Llanos, A. Z. (2011). La ponderación y los derechos fundamentales. ( $\left.1^{\mathrm{a}} \mathrm{ed}.\right)$. Universidad Libre de Colombia, Grupo Investigación Phronesis.

Constitución Política de 1991. Bogotá: Editorial Legis.

Convención Colectiva de Trabajo de la Empresa Ecopetrol S.A.

Colombia, Corte Constitucional. Sentencia T- 422 de 1992 M.P. Eduardo Cifuentes Muñoz.

Colombia, Corte Constitucional. Sentencia C-040 de 1993 M.P. Ciro Angarita Barón.

Colombia, Corte Constitucional. Sentencia C-230 de 1994 M.P. Eduardo Cifuentes Muñoz.

Colombia, Corte Constitucional. Sentencia C-410 de 1994 M.P. Carlos Gaviria Díaz.

Colombia, Corte Constitucional. Sentencia C-445 de 1995 M.P. Alejandro Martínez Caballero.

Colombia, Corte Constitucional. Sentencia T-352 de 1997 M.P. Eduardo Cifuentes Muñoz.

Colombia, Corte Constitucional. Sentencia C-507 de 1997 M.P. Carlos Gaviria Díaz. Colombia, Corte Constitucional. Sentencia T-586 de 1999.

Colombia, Corte Constitucional. Sentencia C-952 de 2000 M.P. Carlos Gaviria Díaz. 
Colombia, Corte Constitucional. Sentencia C-093 de 2001 M.P. Alejandro Martínez Caballero.

Colombia, Corte Constitucional. Sentencia T-1502 de 2000.

Colombia, Corte Constitucional. Sentencia C-1033 de 2002.

Colombia, Corte Constitucional. Sentencia T-403 de 2011.

Colombia, Corte Constitucional. Sentencia C-539 de 2011.

Colombia, Corte Constitucional. Sentencia T-606 de 2013.

Dworkin, R. (1989). Los derechos en serio. Barcelona: Ariel.

Ley 489 de 1998. Organización y funcionamiento de las entidades de orden nacional. Diciembre 29. Diario Oficial 43.464, de 30 de diciembre de 1998.

Ley 1437 de 2011. Código de Procedimiento Administrativo y de lo Contencioso Administrativo. Diario Oficial 47.956 de enero 18 de 2011. 
